\title{
Western privacy and/or Ubuntu? Some critical comments on the influences in the forthcoming data privacy bill in South Africa ${ }^{\frac{1}{2}}$
}

\author{
Hanno N. Olinger ${ }^{\mathrm{a}}$, Johannes J. Britz ${ }^{\mathrm{a}, \mathrm{b}}$ and Martin S. Olivier \\ ${ }^{\mathrm{a}}$ Department of Information Science, University of Pretoria, Pretoria, South Africa \\ ${ }^{\mathrm{b}}$ School of Information Studies, University of Wisconsin-Milwaukee, Wisconsin, USA \\ ${ }^{c}$ Department of Computer Science, University of Pretoria, Pretoria, South Africa
}

\section{Summary}

There is a worldwide concern growing regarding the increasing potential threats to the personal privacy of individuals caused by technologies and governments. The international response of governments has been to draught comprehensive privacy legislation in order to protect their citizen's personal information and to enable their citizens to have control over their personal information. In South Africa, the right to privacy is protected by both Section 14 of the Constitution and the provisions of the Common Law, but at this stage no formal privacy legislation is in place to enforce fair data protection principles. A new Data Privacy Bill is in the process of being draughted by the South African Law Commission and it is taking into account South Africa's unique political and social context as well as international demands made by the global economy. The prime influences acting upon the new Data Privacy Bill are the mandate in the Constitution, the EU Data Protection Directive and the Ubuntu worldview. Ubuntu can be described as a community-based mindset in which the welfare of the group is greater than the welfare of a single individual in the group. In this article, we argue that the EU Data Protection Directive is one of the best articulated privacy laws in existence today and the Ubuntu philosophy has been pressed into service very successfully in 
diverse arenas in South Africa. This paper argues that both influences will be seen in the future Data Privacy Act, but that the EU Data Protection Directive's influence will be preeminent.

\section{Article Outline}

Introduction

Concept of privacy

Ubuntu

Introduction

Definitions of Ubuntu

Concepts of Ubuntu

Core values of Ubuntu

Communalism

Interdependence

Other core values of Ubuntu

Applications of Ubuntu

Privacy within the Ubuntu culture

Worldwide privacy legislation and directives

Introduction

United Nations

United States of America

Europe

Africa

South African privacy legislation

Introduction

South African constitution

South African common law

South African legislation relevant to privacy

Envisaged privacy bill

The Ubuntu factor and data protection

The Ubuntu-western influence

Ubuntu's influence on jurisprudence 
International privacy models as influences

The character of the proposed data privacy bill

Conclusions

References

\section{Introduction}

In June 2004, several major South African newspapers (Kalideen, 2004) published an article that the South African Post Office would sell the personal information of all registered citizens contained in its National Address Database (NAD): “The personal information intended for sale constituted the individual's name, national identity number, home address, post office address as well as telephone numbers" (Pretoria News, 15 June 2004). The personal information contained within the NAD was collected via census records, TV licence payments, telephone accounts held and national identity document records held by the Ministry of Home Affairs.

The personal information of millions of South African citizens was therefore literally put up for sale as a commodity without any legal mechanisms in place to stop this action. Individuals could legally do nothing to prevent the sale of their personal information and they felt a fundamental loss of control with respect to who is allowed to receive their personal information and how much of that information is revealed to a third party. As the situation currently stands, South Africa has no data protection laws in place, which would prevent misuse of personal information stored in the hands of third parties. In South Africa, the right to privacy is recognised by the Constitution (South Africa, 1996) and in the common law. The common law defines privacy as part of an individual's personhood and that harm done to an individual's personhood or personal property is wrong. The sharing of personal information without the consent of the data subject is considered a wrongful act. (The "data subject" is the person whose personal information is being collected, processed or shared.) The South African government has recognised the vulnerabilities and has commissioned the South African Law Reform Commission to investigate the need for a Data Privacy Bill and to make recommendations in this regard. 
The trend to legislate comprehensive privacy laws is driven by the recognition of the increasing potential threats to the personal privacy of individuals worldwide. This perceived threat is fuelled by the pervasive deployment of computer systems together with the exponential increase of data collection, data processing, storage and exchange. The EU, South Africa's biggest trading partner, has legislated comprehensive privacy laws to protect the exchange of their citizen's personal information especially during cross-border flows between any EU member country and a foreign country. Countries outside the EU, including the USA, have responded by drawing up general or specific privacy legislation to accommodate the EU's requirements and to ensure continued international trade, information sharing and e-commerce to function.

The African worldview driving much of African values and social thinking is "Ubuntu” (Broodryk, 2004). The Ubuntu worldview has been recognised as the primary reason that South Africa has managed to successfully transfer power from a white minority government to a majority-rule government without bloodshed (Murithi, 2000). The question is of course to what extent the South African government will attempt to draught a Data Privacy Bill balancing both African values and international legislation. Ubuntu is difficult to define succinctly, but could be best described as a communitybased mindset in which the welfare of the group is greater than the welfare of a single individual in the group (Kwamwangamalu \& Nkonko, 1999, p. 27). Ubuntu espouses a value system in seeming contradiction with current Western values. Western cultures are primarily founded on the political philosophy of Libertarianism, which places a strong emphasis on the rights of the individual in order to protect and empower them. On the other side of the spectrum resides the political philosophy of Communitarianism, which places an emphasis on the good of the community, and especially during ethical decisions the difference between the two sides becomes apparent.

Much of privacy legislation draughted so far seeks to protect the individual against the potential informational exploitation by powerful role players in possession of such personal information. When draughting the upcoming Data Privacy Bill, a potential tension and contradiction can result due to the African frame of reference of placing the interests of the community ahead of that of the individual. 
The main aim of this paper will be to investigate to what extent the Western notion of privacy and the African worldview of Ubuntu influence the nature and character of the forthcoming Data Privacy Bill in South Africa.

The paper is structured as follows. The fist part focuses on the notion of privacy. The second part addresses Ubuntu with the focus on its definitions, applications and the understanding of privacy in the Ubuntu society. The next part deals briefly with international trends in privacy legislation followed by a discussion on the current South African privacy-related legislation. In the last part of the article, we ask the question to what extent Ubuntu can assert itself and influence the current data privacy discourse in South Africa. We came to the conclusion that Ubuntu will have a limited impact on the proposed Data Privacy Act in South Africa.

\section{Concept of privacy}

Substantial work has already been done on the concept of privacy by several authors and this paper will not add to, or change the current understanding of privacy in western cultures. Privacy deals primarily with the personal space and personal information of individuals (Brandeis \& Warren, 1890; Privacy International, 2003; Neethling cited in Britz, 1999), how access to it is controlled (US Congress Office of Technology Assessment, cited in Rosengerg, 1998, p. 138), the freedom of space to exercise autonomy (Clarke, 1999; Milberg, Burke, Smith, \& Kallman, 1995), a balancing of rights and a continuously variable boundary between privacy and publicity (Altman, 1999 cited in Dourish \& Palen, 2003). The most common thread running through the definitions of privacy is the notion of the control of personal information and having autonomous space to act as moral beings.

Several authors have argued that a certain amount ethical relativism does exist and that cultures have differing interpretations on certain ethical issues, of which privacy is one. This can lead to a prioritisation of rights, a justification of rights and the privilege to practice distinctive rights in respective cultures (Bell, 2001; Johnson, 2001). This has an important impact on the way privacy is perceived and interpreted in different cultures. 


\section{Ubuntu}

\section{Introduction}

“Ubuntu” is an African worldview and is driving much of South Africa's values and social thinking (Broodryk, 2004). Ubuntu has also been described as an African phenomenon and an accurate reflection of Africa's historical cultural, legislative and social systems. The term Ubuntu features very largely in several well-known African agenda's such as the African Renaissance and the Millennium Action Plan (Jana, 2001). Beyond that Ubuntu is becoming a globalising concept that is being seriously considered as an alternative to “extractive capitalism” (Van Binsbergen, 2002). Ubuntu is currently being driven and marketed by the political powers and intellectual elite of many countries in Africa as the solution to the poverty, political strife; ethnic conflict experienced in Africa and is an “awakening” of true Africanness. This is especially true of post-1994 South Africa where the political leadership is looking for an ideology to press into service to build a new society. Above that, Ubuntu is seen as an answer to conflict resolution and Restorative Justice (Anderson, 1999; Van Binsbergen, 2001).

\section{Definitions of Ubuntu}

As noted above, Ubuntu is difficult to define succinctly, but we will draw on a few definitions of Ubuntu to illustrate is breadth of interpretation. Louw (2001) describes the concept of Ubuntu within the following phrase:

Umuntu ungumuntu ngabanye abantu” (Nguni languages of Zulu and Xhosa)

The phrase roughly translated into English would mean;

A person is a person through other persons.

This encapsulates the concepts of "humanity," "humanness” and even "humane-ness" and expresses respect and compassion to others (Louw, 2001). Broodryk (2002) states that Ubuntu is essentially:

An ancient African worldview based on the values of intense humanness, caring, respect, compassion, and associated values ensuring a happy and qualitative human community life in a spirit of family. 
Ubuntu could also be described as a community-based mindset in which the welfare of the group is greater than the welfare of a single individual in the group (Kwamwangamalu \& Nkonko, 1999, p. 27).

\section{Concepts of Ubuntu}

Justice Mokgoro explains that Ubuntu is essentially an African philosophy of life, which reflects the African approach and worldview when considering cultural, social and political aspects of life (Mokgoro, 1997). Furthermore Justice Mokgoro states that Ubuntu is a metaphor that describes group solidarity in such a way that the survival of the group depends on this solidarity of individuals to the group. The individual's existence and identity is relative to the group and is defined by the group as well. This is in stark contrast to the Cartesian notion of individuality that states, "I think, therefore I am". The Ubuntu notion of individuality is more complex and multi-facetted and suggests a multiplicity of "I's" —one for each relationship the Ubuntu individual is involved in Louw (1999).

According to Van Binsbergen (2002) Ubuntu recognises the following four attributes of human beings:

- human dignity and equality,

- universal brotherhood,

- sacredness of life,

- "being" is the most desirable state of life (i.e. community-based living).

Human beings are recognised as being all equal, sharing a common basic brotherhood, having the right to life and finding their ultimate meaning and purpose within communities. Privacy as a notion does not function in African philosophical thinking (Coetzee \& Roux, 2002; Ramose, 2002). We argue therefore that this communal African worldview is in contrast to the more individualistic and self-centredness of Western cultures. 


\section{Core values of Ubuntu}

\section{Communalism}

The literature review confirms that Communalism comes across as a foundational cornerstone of Ubuntu. It would be accurate in stating that Ubuntu is communalism in the most fundamental sense of the word. According to Kwamwangamalu and Nkonko (1999, p. 27) communalism is the core value of Ubuntu and implies that the interests of the individual are subordinate to that of the group. The communalist group will focus the interests of each individual member towards those activities and behaviours that will ensure the good of the group. Communalism furthermore believes that once the good of the group is ensured, the benefits will flow through to each individual member. Another associated concept of Ubuntu communalism is that of collective solidarity, meaning that individuals will focus their interests, activities, and loyalties of their own accord, in line with the group's cause and well-being (Mokgoro, 1997). Each individual realises that he is part of a group and that the group depends on his skills, inputs, labour and loyalty in order to survive. The communalist lifestyle also places within each individual a strong sense of belonging - arguably one of the strongest needs in humans today. The communalist lifestyle thus provides each member a sense of purpose and security in relation to that group.

The strong collective thinking of Ubuntu implies that the individual members of the group cannot imagine ordering their lives individualistically without the consent of their family, clan or tribe (Kwamwangamalu \& Nkonko, 1999, p. 27). The communalist lifestyle goes so far in that children are not the sole responsibility of the parents alone, but are the responsibility of the extended family and entire clan of adult members. Individuals are taught, by experience, that an individual cannot live alone or manage life by herself or himself; she/he needs the collective wisdom and experience of others in order to become his best. By becoming her/his best sh/he also will benefit the group as a whole.

One observation about the communalist nature of Ubuntu is that it is sustainable at a local village level, but is difficult to exercise beyond the boundaries of everyday relationships. Individuals have a limited capacity to relate to other people in terms of sheer numbers of relationships, and since relationships are a cornerstone to Ubuntu, the practice of Ubuntu 
occurs primarily within the boundaries of the individual's primary relationships. This does not mean that Ubuntu's ethos and culture are not carried over to other areas, but that it is practised in localities by individuals in groups that know each other well (Scorgie, 2004).

\section{Interdependence}

The second core value of Ubuntu is that of interdependence. According to Mbigi the individual owes his existence to others because "you are because I am" and "I am because you are" (cited in Brack, Hill, Edwards, Grootboom, \& Lassiter, 2003). This is interpreted from the Ubuntu statement, "people are people through other people". Bhengu says that in the context of Ubuntu, a man cannot exist of himself, by himself, or for himself (cited in Kwamwangamalu \& Nkonko, 1999). Therefore, a person exists in a social cluster and has an interpersonal nature, a nature dependant on others to help define and distinguish. The strong communalist and interdependent nature of Ubuntu has established the virtues of patience, hospitality, loyalty, respect, sociability, and sharing among its adherents (Kwamwangamalu \& Nkonko, 1999, p. 27).

Kwamwangamulu and Nkonko further explain that people bound within high-context cultures are strongly interdependent and deeply involved in each other's lives. This means that individuals become entwined with other members of the family, clan or tribe over their lifetime in a series of obligations and expectations. The social value of interdependence is taught in many African proverbs (Kwamwangamalu \& Nkonko, 1999):

- A man here, a man there means no fear. (We can achieve anything if we support one another.)

- The sickness of the eye is the sickness of the nose. (Your neighbour's problem is your problem.)

- A neighbour is a sibling. (Care for your neighbours as family.)

These proverbs indicate the strong bonds of intimacy, mutual support and interdependence found in true Ubuntu societies. 


\section{Other core values of Ubuntu}

Broodryk (2002) expands on the following core values of Ubuntu: (see Table 1).

Table 1.

Ubuntu values.

\begin{tabular}{|l|l|}
\hline Ubuntu core value & Associated social values \\
\hline Humanness & Warmth, tolerance, understanding, peace, humanity \\
\hline Caring & Empathy, sympathy, helpfulness, charity, friendliness \\
\hline Sharing & Unconditional giving, redistribution, open-handedness \\
\hline Respect & Commitment, dignity, obedience, order \\
\hline Compassion & Love, cohesion, informality, forgiveness, spontaneity \\
\hline
\end{tabular}

Broodryk (2002, p. 31) points out that the English word closest to Ubuntu is

"humanness". Humanness implies that all of us are living human beings deserving of

recognition by others in such a way that we all have the right to life. Caring within

Ubuntu does not differ from caring in other cultures, except that it is intensely expressed

in Ubuntu through how people are treated.

The sharing in Ubuntu is called Mahala and is the unconditional sharing of one's excess resources (Broodryk, 2002). Mdluli states that respect is an extremely important value of Ubuntu (cited in Broodryk, 2002). Respect is interpreted to mean the authority of elders over younger people, parents over children and leaders over followers. It also is reflected in humility towards others, and the social structures of law, order and discipline. Finally, compassion in the Ubuntu person is of an intense nature and is defined by the manner in which one lives, and is especially experienced by the rural cultures of Africa more deeply than the urban (Broodryk, 2002). Mangani states that in Ubuntu people treat each other as human beings and not simply as tools or a means to an end (cited in Broodryk, 2002). This touches on the Categorical Imperative of Kant (1968), which states that humans must be seen as an end, and never be treated as a means to an end. 


\section{Applications of Ubuntu}

The benefits of the Ubuntu world-view have been recognised and have been applied to various spheres of life including philosophy, politics, management, business, and the judiciary. In some cases, Ubuntu has been borrowed for expediency and applied in a remote intellectual manner instead of being lived out and experienced. Van Binsbergen (2002) explains that many South Africans today do not live out Ubuntu in the true sense of the word and that they have been taught Ubuntu by reformulation. Politicians and university intellectuals have primarily done this as an abstract model of an African ideal. Ndabele feels that Ubuntu is being over-interpreted by many of the elite in South Africa today and that Ubuntu is no different from the ethical standards promoted in other cultures (cited in Cerff, 2004).

Ubuntu in South Africa has been applied in the following areas:

- Politics — the African Renaissance (Jana, 2001; Louw, 1999).

- Business - through collective learning, teamwork, sustainability, a local community focus, and an alternative to extractive capitalism (Chossek, 2003 cited in Nussbaum, 2003).

- Corporate governance-through the attitudes of fairness, collectiveness, humility (Nussbaum, 2003).

- Restorative justice-through the use of dialogue, collective restitution and healing (Anderson, 1999).

- Conflict resolution and reconciliation - through the Ubuntu ethos of the TRC (Murithi, 2000; Van Binsbergen, 2001).

\section{Privacy within the Ubuntu culture}

During the extensive literature review privacy was not explicitly mentioned anywhere among the Ubuntu writings. Privacy was glaringly absent as a cherished value or right within Ubuntu societies.

When analysing the concepts and values of Ubuntu one can infer directly the implications for privacy and the attitude towards personal privacy. The statements made earlier about the welfare of the community (or group) being more important than that of the individual immediately shows that there is a tension between privacy and social good. The case here 
is that personal privacy might be regarded as not being beneficial for the good of the community. An individual right will only be accepted if it serves the community and in Ubuntu it is difficult to make the case for the social benefit of personal privacy. The culture of transparency and openness in Ubuntu would not understand the need for personal privacy or be able to justify it. Thus, personal privacy would rather be interpreted as "secrecy". This "secrecy" would not be seen as something good because it would indirectly imply that the Ubuntu individual is trying to hide something instead of protecting something — namely her personhood.

The core definition of Ubuntu, "people are people through other people", indicates that there is little room for personal privacy because the person's identity is dependant on the group. The individualistic cultures of the West argue that personal privacy is required for a person to express his true individuality. With Ubuntu individuality is discovered and expressed together with other people and not alone in some autonomous space, and hence personal privacy plays no role in this Ubuntu context.

According to Louw (1999) the individual's identity is relative to the group and is even defined by the group. This has direct implications for the role of privacy in these relationships, because privacy is understood by the Western Cultures as part of the personhood of an individual. If that personhood is relative to the relationships experienced within a group setting then the privacy is relative and by further deduction of lesser importance. The reason we argue this is that the lowest common denominator of relationship in a transparent community will become the dominant level of relationship. An individual in this multiple relationship scenario will arguably experience some more "open” relationships than other more "closed" relationships. The more open relationships will be shared as common knowledge within the community because of the nature of human networks and the human need to share ideas and thoughts. Therefore, the details of the open relationships will become the knowledge that all immediate members of the community share of that individual. Therefore the closed, more private, relationships will eventually cease to exist in any meaningful way due to the other persons knowing more personal information of that specific individual. This is contrary to the concept of requiring privacy to form special relationships. By inference privacy cannot meaningfully exist in these relationships. 
The idea of multiple "I's" (Louw, 1999) also indicates the same lack of privacy, because it suffers a similar fate as the relative identity issue discussed in the previous paragraph. The Ubuntu culture of openness and transparency is in strong contrast to the western culture of privacy and private autonomous spheres. While openness and transparency do not entirely negate privacy, they certain diminish its importance significantly, because privacy would be a hindrance to openness and transparency. Therefore, we argue in such an open culture of Ubuntu, privacy plays a lesser role.

According to Scorgie (2004), some privacy is enjoyed in Ubuntu communities even though privacy is seen as secondary to relationships and relationship-building. People are understood to have their own unique thoughts, ideas, characteristics and accomplishments. People have privacy in the context of these aforementioned items-a sense that these are the private possessions of an individual. This idea does not run counter to the Western concept of privacy as dignity and as a part of an individual's personhood. Scorgie (2004) furthermore states that in rural villages in the South African province of KwaZulu Natal there is not a strong sentiment towards privacy and that privacy has expressed itself as a response to community envy. Individuals that enjoy material success beyond the boundaries of the villages in urban employment become victims of community envy and tend to become "secretive" or "private" about these successes (Scorgie, 2004). This is a unique form of privacy that has originated to defend the individual against the community, and is by no means the norm for communitarian societies.

An aspect of privacy in the rural communalist cultures is one of the privacy of ownership, in other words, the community recognises an individual's private ownership of material possessions.

The Ubuntu communal system will impose a type of "Panopticon effect" upon the members of the respective community through the openness, transparency and surveillance nature of their interrelationships. Since there is little freedom from observation in a communal system, people's inner dealings and activities become obvious to the rest of the community.

One final argument we wish to make regarding privacy within the Ubuntu culture is that of consent — the requirement that individuals cannot really order their lives without 
consent from family, clan and the community (Kwamwangamalu \& Nkonko, 1999, p.

27). This requirement is in contradiction to the notion of autonomy in order to make free moral decisions. To that end privacy is required to ensure personal autonomy and hence provide the ability to make those free moral decisions.

Thus, in sum, we have shown that within the Ubuntu culture privacy has been relegated to a position of lower importance than in the Western cultures. This fact could possibly have a bearing on the nature and character of the Data Privacy Bill and eventually Data Privacy Act.

\section{Worldwide privacy legislation and directives}

\section{Introduction}

Comprehensive privacy legislation exists in most countries around the world today of which the EU's Data Protection Directive is probably the best known of its kind. Governments typically draught and enact privacy legislation while international bodies and organisations would set down privacy directives for their members to voluntarily adhere to.

Personal privacy is usually enforced by the restriction of the flow of personal information. The focus of privacy legislation is generally to provide the individual (a) autonomous space and to provide the (b) ability to control the flow of personal information. The latter laws are usually referred to as Data Protection Laws. Data protection laws are a recent phenomenon due to the recent advent of modern computing and find their first expression in the 1970s. The USA draughted their first privacy legislation in 1974, Germany in 1977, and France in 1978 and the number of countries has grown to more than thirty in total (Law Reform Commission, 2003).

\section{United Nations}

The first mention of personal privacy is found in Article 12 of the UN's Universal Declaration of Human Rights (UN, 1948). The declaration focuses on territorial and communications privacy but not on the other dimensions of personal privacy. 


\section{United States of America}

The United States Constitution does not specifically mention privacy as a right, but it can be inferred from the text of the 4th Amendment to the Constitution. The 4th Amendment focuses on freedom from unreasonable searches and seizures (United States of America, 1992).

\section{Europe}

The European Union (EU, 1995) enacted their benchmark privacy directive in 1995 and is called by its short form as the Data Protection Directive (Directive 95/46/EC of the European Parliament). This Data Protection Directive guarantees European citizens a fundamental political right to privacy across every member state of the EU (European Union, 1995; Kilian \& Funkat, 2000, p. 1061; St. Amant, 1999, p. 5). The important articles in the Directive, Articles 25 and 26, discuss data protection principles and derogations that impact non-EU countries trading with the EU. These two articles of the Data Protection Directive state the non-EU countries must provide "adequate levels of protection” when processing personal information of EU citizens. If the levels of protection are deemed not to be adequate, then the EU Commission will prevent the information transfer to the third country (EU, 1995). The data subject (i.e. EU citizen) has the right to allow the transborder flow of his or her personal information if it is necessary to conclude a contract, a legal requirement, or if it is in the vital interests of the individual (EU, 1995). Thus, explicit consent is required from the individual before his/her personal information is used by third countries with inadequate privacy regimes.

The EU's increasingly dominant position in international trade and politics has been the main driver for many non-EU countries to adopt adequate privacy legislation. As mentioned earlier the privacy protection measures are needed to allow international trade, information sharing and e-commerce to continue. It is important to point out that the EU's privacy regime fosters a socio-political right to privacy that has personal dignity at its core. This is in stark contrast to the US notion of liberty combined with varying sectoral privacy laws. 


\section{Africa}

The African Charter of Human and Peoples’ Rights adopted in June 1981 (OAU, 1982) fails to mention privacy at all, while the African Charter on the Rights and Welfare of the Child (OAU, 1990) does mention privacy quite clearly, but in a limited context.

The failure to mention privacy indicates that privacy was simply not seen as a necessary right for Africans to live freely and peaceable. The charter instead focuses on those Ubuntu values of human equality, dignity, dialogue, freedom of choice for his solidarity and community security (OAU, 1982). The African Charter was established after the UN Charter on Human Rights where the right to privacy is explicitly stated. It is somewhat strange that that privacy is mentioned as a right for a child in the Charter of 1990 but has not been mentioned in the earlier Charter of 1981 as a right for all human beings. As mentioned before, we can only suggest that firstly, by 1990 the concept of privacy had begun to emerge as an important right and secondly, that children are as regarded as vulnerable and in need of a greater reinforcement of their rights. South Africa and Tunisia are also the only two countries on the African continent that have made substantial progress towards the legal protection of personal data of individuals (Privacy Knowledge Base, 2005).

\section{South African privacy legislation}

\section{Introduction}

South Africa has no Data Privacy Act yet, but certain important provisions and references for the need for personal privacy have been mentioned in several legal instruments. The Common Law provides for personality rights such as physical integrity, freedom, reputation, dignity and privacy (Britz \& Ackermann, 2006). Above that the right to privacy is enshrined in the Constitution of the Republic of South Africa (South Africa, 1996).

\section{South African constitution}

The provisions for privacy in the Constitution place the South African government under obligation to provide the relevant legislation to protect these privacy rights of South 
African citizens. By briefly analysing the statements made in Section 14 of the Constitution it can be seen that the dimensions of privacy addressed are:

- freedom from intrusion,

- freedom from disclosures of personal information,

- personal autonomy.

The terms "possessions" in Section 14c could be interpreted to range from tangible property through to intangible property such as personal reputation, intellectual property, personal photographs, and personality-related concepts such as personal preferences.

\section{South African common law}

The Common Law emphasises privacy as part of a person's inviolate personality and as such enjoys protection while the Constitution provides for privacy as a constitutional right. A constitutional right is the highest form of right a citizen (or juristic person) may enjoy, because it binds all state organs, the judiciary and the executive to ensure these rights are protected and entrenched for citizens (Law Commission, 2003).

In certain common law rulings, the dignity of an individual was widely interpreted and included a host of personality rights including privacy (Geldenhuys, 1993). Within the Constitution, the rights to dignity (Section 10) and privacy (Section 14) are separated with both enjoying equal importance in the eyes of the Constitution (Law Commission, 2003, p. 45). Thus, privacy has advanced from the Common Law as being part of the list of personality rights of an individual up to becoming a Constitutional Right in the final Constitution of 1996.

Within the ambit of the common law, an invasion of an individual's privacy will be interpreted as an impairment of a person's personality. This can provide the victim a legal ground for civil claims. Within the ambit the constitutional right to privacy, an invasion of privacy will be seen as an illegal act or an unconstitutional act.

\section{South African legislation relevant to privacy}

Even though no Data Privacy Act exists yet, several other acts touch on aspects of privacy and the most important ones to mention are (Britz \& Ackermann, 2006; Privacy International, 2003): 
- The Provision of Access to Information Act (South Africa, 2000).

- The Electronic Communications and Transaction Act (South Africa (2002a) and South Africa (2002b)).

- The Interception of Communications and Provision of Communication-related Information Act (South Africa (2002a) and South Africa (2002b)).

The first act mentioned in the bullets, the Promotion of Access to Information (hereafter referred to as "PAIA"), deals with allowing individuals to obtain access to their personal information, but it does not regulate who and how that personal information may be corrected and controlled by the individual (Law Commission, 2003, p. 1). Privacy is strongly related by how personal information can be controlled by the information owner, and this provision is missing in the PAIA. It is specifically, the failure of the PAIA in comprehensively addressing privacy that a separate Data Privacy Bill is in the process of being draughted and legislated.

The second act of note is the Electronic Communications and Transactions Act (hereafter referred to as "ECT Act"), focuses on establishing a framework within which ecommerce can be regulated (Michalsons \& Hughes, 2004). One of the supporting objectives of the ECT Act is to protect individuals engaged in e-commerce and this expresses itself in Chapter 8 as a voluntary regime of data protection principles for personal information (Michalsons \& Hughes, 2004). Businesses can voluntary decide to subscribe to these data protection principles and hopefully create favourable business opportunities by promising to safeguard the personal information of customers. The ECT Act does therefore, not allow absolute protection under the law for personal privacy. The third act to be mentioned is the Interception of Communications and Provision of Communication-related Information Act (hereafter referred to as "Surveillance Act"). The Surveillance Act primarily focuses on the communications aspect of privacy by prohibiting all wiretaps and surveillance of all personal communications. The only exception allowed is either for law enforcement agencies to perform wiretaps during criminal investigations or when special permission has been obtained (Britz \& Ackermann, 2006; Privacy International, 2003).

The South African legislation in place at the moment each touches on an aspect of privacy or mentions privacy as a fundamental right. There is however, no blanket 
legislation broadly addressing privacy as a fundamental political right in balance with other rights.

\section{Envisaged privacy bill}

As we already pointed out, the South African Law Commission is in the process of finalising a draught privacy bill based on a paper entitled Privacy and Data Protection (Issue Paper no. 24). The discussion paper was published in 2003 and it invited comments, and the draught bill will be published and submitted to the South African Parliament during 2006. The paper (Issue Paper no. 24) deals with a variety of issues including why people value privacy, commercial transactions and the protection of consumer privacy, credit bureaux, passive information gathering (cookie files, etc.), stalking and privacy and health information. The outcome of the privacy bill is the writing of a new Data Protection Act. During 2005 a concept bill was published for public comment.

\section{The Ubuntu factor and data protection}

\section{The Ubuntu-western influence}

The question is whether Ubuntu can assert itself and influence privacy legislation related to data protection more than international trends in this field. There are other important factors driving legislation regarding the protection of data in South Africa. The most important is the EU's pressure on non-EU countries to process personal information of EU citizens according to the EU directives. As a result of the EU's stance, information sharing and trade could be jeopardised if data protection is not in place. These are strong influences and drivers for the enactment of a Data Privacy Act in South Africa. This leads to the following question: To what extent can Ubuntu, which is a social-cultural value, plays a role in the domestic legal discourse regarding the protection of personal data of South Africans?

\section{Ubuntu's influence on jurisprudence}

We have briefly shown how widely the principles of Ubuntu have been implemented in politics, business, corporate governance and restorative justice. The influence of Ubuntu 
has not been minor, but quite broad and useful. The aspects of Ubuntu applied in the four areas mentioned above relate primarily to Ubuntu's African roots, humanness in leadership, consensus, dialogue and reconciliation.

Madam Justice Yvonne Mokgoro (1997) makes a case for Ubuntu's influence in future South African jurisprudence based on:

- The adoption of the Ubuntu values of dignity and equality in the Constitution of South Africa.

- The successful application of Ubuntu values in forming national reconciliation and forgiveness between the various race groups.

(Justice Mokgoro is the Chairperson of the South Africa Law Commission, which has drawn up the comprehensively researched Issue Paper No.24 on Data Privacy. Her opinions regarding Ubuntu and jurisprudence should be seriously considered when her dual role as Law Reform Commission Chairperson and her past experience with Ubuntuist jurisprudence is considered.)

It cannot be denied that the road to reconciliation in South Africa has been successfully negotiated so far. Archbishop Tutu has given the credit for this to the application of Ubuntu values and principles (Murithi, 2000). Chapter 16 of the Interim Constitution of South Africa clearly states that reparation and Ubuntu are needed to ensure national unity, peace, reconciliation and reconstruction:

... These can now be addressed on the basis that there is a need for understanding but not for vengeance, a need for reparation but not for retaliation, a need for Ubuntu but not for victimization (Interim Constitution of South Africa, Act 200 of 1993, Chapter 16:

National Unity and Reconciliation)

However, it is interesting to note that in the final constitution of 1996 Ubuntu is not mentioned anywhere explicitly within the Constitution's articles or preamble. There has been a slight shift between both versions of the Constitution where Ubuntu was a stronger focus during the Interim Constitution than in the Constitution of 1996. Dugard (1997) argues that essentially both constitutions are similar and that the principles of the Interim Constitution have been carried over to the final Constitution of 1996. The description of the right to privacy is almost unchanged between the two versions of the Constitution. Interim Constitution of South Africa (Act 200 of 1993) Section 13: Privacy: 
Every person shall have the right to his or her personal privacy, which shall include the right not to be subject to searches of his or her person, home or property, the seizure of private possessions or the violation of private communications.

Constitution of South Africa (Act 108 of 1996) Section 14: Privacy:

Everyone has the right to privacy, which includes the right not to have:

- their person or home searched;

- their property searched;

- their possessions seized, or

- the privacy of their communications infringed.

We are of the opinion that further development of privacy legislation in South Africa the influence of Ubuntu will be of less significant than originally suggested in the 1993 interim Constitution. There are a number of reasons. Firstly, although human dignity is the prime Ubuntu value that has been infused into the Constitution of South Africa there exist no Ubuntu-specific references to privacy in the Constitution neither in current privacy related legislation in South Africa. The strengths of Ubuntu, in influencing the Constitution, are merely indirect in terms of its emphasis on human dignity and human equality.

Secondly, and related to our first argument, we would like to point out that although Ubuntu can, and has indeed influenced jurisprudence in South Africa, it could only be so in those areas where Ubuntu has a strong expression and philosophy, but not where Ubuntu leaves a vacuum of philosophy. In the case of privacy, Ubuntu leaves little doubt that privacy is not esteemed as a priority for the community or for the individual. Therefore, with respect to privacy, we argue that Ubuntu cannot guide or influence legislation significantly more than for example the European Union's Data Directive's principles.

Thirdly we argue that the notion of Ubuntu is to a certain extent an idealistic concept in the world of economic realities that is regulated and controlled by international standards, rules and regulations such designed by amongst other the World Intellectual Property Organisation (WIPO) and the EU. Ubuntu is exclusive and limited to the African way of life. It is not incorporated into the global trade agreements and its very nature is cultural and not legal or economical. This economic and legal realities will make it very difficult 
for the South African policy makers to include those elements of Ubuntu into legislation that does not translate well into international trade of personal data.

Thus, the three arguments in sum show that Ubuntu could have been overextended and over-idealised in its abilities and its applicability for societal challenges. Therefore, we argue that the Ubuntu influence in privacy jurisprudence will be weaker and that the guidance for formulating the Data Privacy Bill—and eventually the act—will be found in other sources.

\section{International privacy models as influences}

The two most influential models of privacy legislation can be found in the USA and the $\mathrm{EU}$, and due to the effects of globalisation their potential influence on privacy legislation could be felt on South Africa's shores. As discussed before, the US culture of privacy is one of liberty while the European culture is one of dignity. If Ubuntu were compared to the two cultures of privacy, it would lean closer to the European culture of privacy. The reason for this is that the Ubuntu worldview and the European culture of privacy both share dignity as a very important cornerstone. When comparing Ubuntu and the US culture of privacy, where personal space and autonomy are very important, then there is little overlap or commonality. Whiteman (2003) researched the US and EU models-, and interpretations of privacy and performed an analysis of the differences between these two western cultures of privacy. We have summarised the salient themes of these privacy models in Table 2.

Table 2.

Comparison between the US and European privacy frameworks.

\begin{tabular}{|l|l|l|}
\hline & \multicolumn{2}{|l|}{ Privacy framework } \\
\hline & United States of America & European Union \\
\hline 1 & Liberty & Dignity \\
\hline 2 & Economic right & Political right \\
\hline 3 & Sectoral & Continental \\
\hline
\end{tabular}




\begin{tabular}{|l|l|l|}
\hline & \multicolumn{2}{|l|}{ Privacy framework } \\
\hline & United States of America & European Union \\
\hline 4 & No oversight agency & EU Commission \\
\hline 5 & Fragmented & Comprehensive \\
\hline 6 & Capitalist & Cultural \\
\hline
\end{tabular}

In our opinion the European model of privacy should become the more dominant influence of the two privacy models when draughting the final Data Privacy Bill in South Africa. There will be other minor influences from other countries, but the EU's comprehensive privacy model is the best-articulated privacy legislation in existence today. It elevates personal privacy to a new level as a political right. The reasons why we favour the EU's privacy legislation as the dominant influence on South African privacy legislation are the following:

- The core expression of privacy is to protect dignity (which is in harmony with the spirit of Ubuntu).

- The privacy rights are comprehensive (which is in line with the Constitution's mandate).

- The privacy rights are political.

- The EU enjoys strong trade links with South Africa.

- The harmonisation of international privacy laws (in line with the EU Data Protection Directive).

Firstly, the protection of dignity (Whiteman, 2003) is a core expression of the EU's Data Protection Directive. This overlaps with Ubuntu's concept of human dignity, the South African Constitution's principle of dignity as well as the Common Law's concept of personal dignity.

The Republic of South Africa is one, sovereign, democratic state founded on the following values:

- Human dignity, the achievement of equality and the advancement of human rights and freedoms.

- Non-racialism and non-sexism.

- Supremacy of the constitution and the rule of law. 
- Universal adult suffrage, a national common voter's roll, regular elections and a multiparty system of democratic government, to ensure accountability, responsiveness and openness.

(Constitution of the Republic of South Africa [Act 108 of 1996] Chapter 1, Section 1.) Dignity, the right thereto, and the protection thereof are found widely in South African jurisprudence and should therefore find their way into future privacy legislation. Since dignity is an accepted and understood value in South African jurisprudence it will find the similar values of dignity in the EU Data Protection Directive as a welcoming point of commonality. For this reason, we argue that the EU Data Protection Directive will find favour with South African legislators and be used as a reference model to draw up the Data Privacy Bill and eventually the Data Privacy Act.

Secondly, the privacy rights described in the EU Data Protection Directive are comprehensive and compulsory for all EU member states to comply with. ${ }^{1}$ The right to privacy has also been elevated to the highest level possible via the EU Data Protection Directive applicable to all sectors in the EU. The South African Constitution (1996) enshrines the right to privacy as a constitutional right, which is the highest order of protection and embodiment of a right possible. Thus in both instances, privacy is highly esteemed and granted as a right.

Thirdly, since the EU is the major trading partner with South Africa, its directives, charters and protocols will have an influence and direct bearing on South Africa. A case in point is the very Data Protection Directive, which states that any personal information flowing to a third country must provide adequate protection:

The Member States shall provide that the transfer to a third country of personal data which are undergoing processing or are intended for processing after transfer may take place only if, without prejudice to compliance with the national provisions adopted pursuant to the other provisions of this Directive, the third country in question ensures an adequate level of protection (Directive 95/46/EC of the European Parliament, Chapter IV: Article 25: Principles).

South Africa will have to comply in order to facilitate the free flow of information, which is a prerequisite to economic activity and for e-commerce to function properly. The best 
way to ensure that adequate privacy protections are in place is to implement a privacy regime of the same order as the European model.

Lastly, the prime reason that South Africa will take its cue from the EU Data Protection Directive is that there is a worldwide trend to harmonise privacy legislation using the EU model as a basis (Law Commission, 2003). The Law Commission (2003) speaks of a convergence and harmonisation of privacy models to such an extent that there is really only one global approach to choose from.

Thus, to summarise, it seems the argument will be that the best option for South Africa is to take its cue from the EU Data Protection Directive and design a Data Privacy Bill of similar nature to ensure harmony with international trends and to ensure continued trade in an e-world.

\section{The character of the proposed data privacy bill}

The prime guiding influences that will shape the nature of South Africa's Data Privacy Bill will be the Constitution's mandate for privacy, the EU Data Directive as model and the preservation of personal dignity for the individual South African citizen.

The Data Privacy Bill will firstly provide for comprehensive privacy legislation to protect the individual against State abuses or public abuses. The Bill will furthermore be a balance of the constitutional approach of the EU Data Directive and the commercial approach of the US sectoral legislation (Louw, 2005), but the emphasis will be on the former approach. The latter influence will be taken into account in order to receive the buy-in of the commercial and business sectors. We are of opinion that Ubuntu will find its place and influence in the Bill, and eventually the Act in an indirect manner via the concept of human dignity.

\section{Conclusions}

International Privacy Models, such as the EU Data Protection Directive, as well as Ubuntu (to a lesser extent), will influence the Data Privacy Bill. Some characteristics of the Data Privacy Bill, such as dignity and equality will be common characteristics of both the EU Data Protection Directive and Ubuntu. 
It has been argued that Ubuntu has had a wide influence and application in South Africa post-1994, and that Ubuntu has its strengths and weaknesses. Ubuntu has a strong influence and role to play in politics for shaping societal values, in business, in conflict resolution and even in corporate governance. However, in defining and guiding legislation on privacy, Ubuntu does not possess an advanced concept of privacy and model of privacy that the EU Data Protection Directive would have.

We have therefore argued that both influences would find sufficient expression in the Data Privacy Bill, but that the EU Data Protection Directive has the edge in its ability to influence.

\section{References}

Anderson (1999) Allison M. Anderson, Restorative justice: The African philosophy of Ubuntu and the diversion of criminal procedure, School of Law, University of the North, South Africa (1999).

Bell \& Daniel (2001) Bell, Daniel (2001). Communitarianism. Stanford encyclopaedia of philosophy, Winter 2001. Retrieved September 2004, from

http://plato.stanford.edu/archives/win2001/entries/communitarianism//.

Brack, Hill, Edwards, Grootboom, \& Lassiter (2003) Greg Brack, Michele Hill, Dana

Edwards, Nomalanga Grootboom and Pamela Lassiter, Adler and Ubuntu: Using Adlerian principles in the New South Africa, Journal of Individual Psychology 59 (2003) (3), pp. 316-326.

Brandeis \& Warren (1890) Louis Brandeis and Samuel Warren, The right to privacy, Harvard Law Review 4 (1890) (5), pp. 193-220.

Britz (1999) J.J. Britz, Technology as a threat to privacy. In: A. Kent, Editor, Encyclopaedia of library and information science Vol. 65, ACE Production, New York (1999), pp. 295-305.

Britz \& Ackermann (2006) J.J. Britz and M. Ackermann, Information, ethics and the law, Van Schaik, Pretoria (2006).

Broodryk (2002) Johan Broodryk, Ubuntu: Life lessons from Africa (2nd print), Ubuntu School of Philosophy, Pretoria, South Africa (2002). 
Broodryk \& Johan (2004) Broodryk, Johan (2004). Interview with J. Broodryk (Garsfontein-Pretoria), 17 May.

Cerff \& Karen (2004) Cerff, Karen (2004). Exploring Ubuntu and the African

Renaissance: A conceptual study of servant leadership from an African perspective.

Servant Leadership Roundtable, Regent University, August. Retrieved September 2004,

from 〈http://www.regent.edu/acad/cls/2004SLRoundtable/cerff-2004SL.pdf \.

Clarke \& Roger (1999) Clarke, Roger (1999). Introduction to dataveillance and information privacy, and definitions of terms. Department of Computer Science, Australia National University. Retrieved August 2004, from

http://www.anu.edu.au/people/Roger.Clarke/DV/Intro.html/.

Coetzee \& Roux (2002) Pieter H. Coetzee and Abraham P.J. Roux, Philosophy from

Africa (2nd ed.), Oxford University Press, New York (2002).

Dourish \& Palen (2003) Paul Dourish and Leysia Palen, Unpacking “Privacy” for a networked world, Communications of the ACM 5 (2003) (1), pp. 129-136.

Dugard (1997) John Dugard, International law and the South African constitution, European Journal of International Law 8 (1997) (1), pp. 77-91.

European Union (1995) European Union. (1995). Directive 95/46/EC of the European Parliament and of the Council of 24 October 1995. Official Journal of the European Communities of 23 November 1995, Brussels.

Geldenhuys (1993) Geldenhuys, T. (1993). Die regseskerming van inligting. Doctor Legium, University of South Africa.

Jana (2001) Priscilla Jana, African renaissance and the Millennium action plan, African Journal of Philosophy, Quest XV (2001) (1-2), pp. 41-46.

Johnson (2001) Deborah G. Johnson, Computer ethics (3rd ed.), Prentice-Hall, Upper

Saddle River, NJ (2001).

Kalideen \& Nadine (2004) Kalideen, Nadine (2004). Post office to sell your name.

Pretoria News, 15 June.

Kant \& Immanuel (1968) Kant, Immanuel (1968). Kritik der practischen Vernunft. Kants Werke-Akademie-Textausgabe, Band 5. Berlin: Walter de Gruyter \& Co.

Kilian, Wolfgang, Funkat, \& Dorte (2000) Kilian, Wolfgang, \& Funkat, Dorte (2000).

Structuring legal knowledge on data protection: The EU-data protection research project 
DAPRO. Database and Expert Systems Applications. In Proceedings. Eleventh international workshop. 4-8 September (pp. 1061-1068).

Kwamwangamalu \& Nkonko (1999) Kwamwangamalu and M. Nkonko, Ubuntu in South Africa: A sociolinguistic perspective to a Pan-African concept, Critical Arts Journal 13 (1999) (2), pp. 24-42.

Law Commission. (2003) Law Commission. (2003). South African Issue Paper 24Project 124, Privacy and Data Protection. Johannesburg.

Louw \& Andre (2005) Louw, Andre (2005). Interview with A. Louw. Researcher of the South African Law Reform Commission (Pretoria), 31 March.

Louw \& Dirk (1999) Louw, Dirk (1999). Ubuntu: An African assessment of the religious other. The Paideia Project. In Proceedings from the twentieth world congress of philosophy, 10-15 August 1998.

Louw (2001) Dirk Louw, Ubuntu and the challenges of multiculturalism in post-apartheid South Africa, African Journal of Philosophy, Quest XV (2001) (1-2), pp. 15-40.

Michalsons, Lance, Hughes, \& Brendon (2004) Michalsons, Lance, \& Hughes, Brendon (2004). Guide to data privacy law in South Africa. Retrieved May 2004, from http://www.michalsons.com//.

Milberg, Burke, Smith, \& Kallman (1995) Sandra Milberg, Sandra Burke, Jeff Smith and Ernest Kallman, Values, personal information, privacy and regulatory approaches, Communications of the ACM 38 (1995) (12), pp. 65-74. Mokgoro \& Yvonne (1997) Mokgoro, Yvonne (1997). Ubuntu and the law in South Africa. Seminar Report of the Colloquium. Johannesburg: Konrad-Adenauer Stiftung. Murithi (2000) Timothy Murithi, Practical peacemaking wisdom from Africa: Reflections on Ubuntu, United Nations, Programme in Peacemaking and Preventive Diplomacy, New York (2000).

Nussbaum (2003) Barbara Nussbaum, Ubuntu and business: Reflections and questions, World Business Academy 17 (2003) (3), pp. 1-15.

OAU (1982) Organisation of African Unity (OAU). (1982). African (Banjul) charter on human and peoples' rights. OAU Document. CAB/LEG/67/3 rev. 5, 21 I.L.M. 58. OAU (1990) Organisation of African Unity (OAU). (1990). African charter on the rights and welfare of the child. OAU Document. CAB/LEG/24.9/49. 
Privacy International (2003) Privacy International. (2003). Privacy and human rights 2003: Overview. Received October 2004, from /http://www.privacyinternational.org/\%. Privacy Knowledge Base (2005) Privacy Knowledge Base. (2005). Received May 2005, from (http://www.privacyknowledgebase.com/document.jsp?docid=REFDPMEA). Ramose (2002) Mogobe Ramose, African Philosophy through Ubuntu, Mond Books Publishers, Zimbabwe (2002).

Rosengerg \& Richard (1998) Rosengerg, Richard (1998). Privacy protection on the Internet: The marketplace versus the state. In Wiring the world: the impact of information technology on society. Proceedings of the 1998 international symposium, 12-13 June (pp. 138-147).

Scorgie \& Frans (2004) Scorgie, Frans (2004). Ubuntu in Practice. HIVAN Research Associate. (Comments received by e-mail.) E-mail to: HN Olinger (Hanno.Olinger@Kumbaresources.com) (6 November).

South Africa (1996) South Africa, Constitution of the Republic of South Africa, Act 108 of 1996, Government Printer, Pretoria (1996).

South Africa (2000) South Africa, Promotion of Access to Information, Act 2 of 2000, Government Printer, Pretoria (2000).

South Africa (2002a) South Africa, Electronic Communications and Transactions, Act 25 of 2002, Government Printer, Pretoria (2002).

South Africa (2002b) South Africa, Regulation of interception of communications and provision of communication-related information, Act 70 of 2002, Government Printer, Pretoria (2002).

St. Amant \& Kirk (1999) St. Amant, Kirk (1999). Information export in the electronic environment: An overview of the EU data privacy directive and the US response. Professional communication conference, 1999. Communication jazz: Improvising the new international communication culture. IEEE international symposium, 7-10 September (pp. 5-11). (1948) United Nations (UN). (1948). Universal declaration of human rights. General Assembly Resolution 217 A (III) of 10 December 1948. New York. 
United States of America (1992) United States of America. (1992). Constitution of the United States of America. Washington, DC, USA: Government Printer. Retrieved August 2004, from /http://usinfo.state.gov/usa/infousa/facts/funddocs/consteng.htm〉. Van Binsbergen \& Wim (2001) Van Binsbergen, Wim (2001). Reconciliation: A major African social technology of shared and recognised humanity (Ubuntu). Philosophical Faculty, Erasmus University, Rotterdam, The Netherlands. Retrieved September 2004, from 〈http://www.shikanda.net//.

Van Binsbergen \& Wim (2002) Van Binsbergen, Wim (2002). Ubuntu and the globalisation of Southern African thought and society. Philosophical Faculty, Erasmus University, Rotterdam, The Netherlands. Retrieved May 2004, from http://www.shikanda.net//.

Whiteman \& James (2003) Whiteman, James (2003). The two western cultures of privacy: Dignity versus liberty. Public Law \& Legal Theory Research Paper Series, Research Paper, Vol. 113(64), Yale Law School.

This article is based on a paper presented at the CEPE Conference in 2005.

Corresponding author. Department of Information Science, University of WisconsinMilwaukee, Wisconsin, USA. Tel.: +1 414229 4709; fax: +1 4142296699. 